\title{
Albanon
}

Revistë kulturore

\section{Fjalësimi poetik i botës si strategji e komunikimit sublim (tragjedia "Akili” i Et'hem Haxhiademit)}

Dr. Durim Çaça

Ushqyer me ideale kulturore dhe atdhetare të kohës së mendimit të ri intelektual të "neoshqiptarizmit", si dhe nga kultura klasike greko-romake dhe filologjia neoklasiciste gjermane, Et'hem Haxhiademi projektoi tragjedi me një madhështi heroike, të një ligjërimi të ngritur dhe të një fjalësimi sublim. Ai na shpërfaqet si një autor me një akt të ri ligjërimor estetik, me veçanësi të dallueshme, jo vetëm për kohën e vet, por dhe sot, pas afro një shekulli të krijimit të kësaj vepre artistike.

\section{a) Fjalësimi poetik i botës si strategji e komunikimit sublim.}

Fjalësimi i botës përmes përshkrimit dhe rrëfimit të saj, realizohet në tragjedinë "Akili” përmes një forme poetike gjuhësimi të lartë, në përshtatje me herojtë mitologjikë, të zbritur nga madhështia mitike e fuqisë dhe përjetësisë hyjnore, (Akili, Priami, Paridi, Polikseni, protagonistët e veprës dramatike në fjalë), në terrenin real të dramës së përditshme njerëzore. Autori fjalëson botën, përshtat përshkrimin e tij, me botën antike, por dhe me botën morale aktuale të kohës së vet. Ai e arrin këtë fjalësim, përmes rrëfimit jo të të gjithë mitit për heroin homerik, por vetëm të episodit tragjik, të vrasjes me pabesi të Akilit. Autori, brenda atmosferës mitologjike dhe përmes frymës heroike të asaj bote (nëpërmjet intertekstit, kujtimeve, referimeve, presupozimit të ngjarjeve dhe të bëmave të mëparshme të herojve), krijon një lloj interpretimi të mitit, një tekst të ri, të imagjinatës dhe strategjisë së tij të komunikimit estetik, nëpërmjet kësaj vepre dramatike. 
Kompozimi dialogjik i tekstit dramatik ${ }^{1}$ nuk është vetëm i natyrës artistike të kësaj gjinie letrare. Mimetisi (imitimi) i dialogimit të individëve njerëzorë deri në një dialogjizëm kundërshtie e konfliktualiteti, të ngjashëm me atë dramacitet që përfton ky ndërveprim gjuhësor në situatën e vërtetë reale të aktit bisedor, është dhe modelim, rikrijim, inskenim diskursi, ngjarjeje dhe shpërfaqjeje ligjërimore. Si dialogjizmin ndërveprues, (ligjërimin e hapur, të mirëfilltë të interlokutorëve bashkëbisedues, të personazheve në skenën e konfliktit dramatik), ashtu dhe dialogjizmin e brendshëm monologjik, i gjejmë në të gjithë strukturën thurëse të tragjedisë në shqyrtim:

Priami: Parid, dashnij' e madhe ty t'verbon, / Prandaj ndëgjo t'yt at si t'këshillon Ajo e huej asht, nuk i zihet besël Dhe ti kët' luftë merr për shembëllesë;/...

Paridi: Ç'ligjron me muë ti kshtu, o mbret Priam?/ M'zemrove tepër, ndonse at të kam,/...

Akili: O ti hyjnesh' e dashunis s'bekueme./ O Afërdit', sa zjarr të madh më dhe!l Porah,

si zemrën t'ime të përvluemel Të thyeme fare dhe pa shpres'e pe, (Haxhiademi, 1, 2000: 89-90, 127).

$\mathrm{Në} \mathrm{analizën} \mathrm{pragmatike} \mathrm{edhe} \mathrm{të} \mathrm{një} \mathrm{bisede} \mathrm{fiksionale} \mathrm{(} \mathrm{të} \mathrm{një} \mathrm{dialogimi}$ dramatik imagjinativ), një vend me rëndësi zënë elementët deiktikë, ${ }^{2}$ siç janë dëftimi i personave (vetëve) bashkëbisedues dhe i roleve të tyre si pjesëmarrës në shkëmbimin gjuhësor; dëftimi shoqëror i statusit publik, familjar, farefisnor të ndërfaluesve në skenën bisedore; dëftimi i akteve të tyre ligjërimore paraprirëse, si kontekst ku vendoset dialogimi fiksional i situatës së aktualizuar ligjërimore; dëftimi i kohës dhe vendit të ndërveprimit gjuhësor të ligjëruesve interlokutorë, - të gjitha këto elemente, parë si një mimetis i një situate reale të aktit bisedor. Sepse "dëftimi rrok marrëdhëniet ndërmjet strukturës së gjuhës dhe konteksteve në të cilat ajo përdoret. Teorikisht ai është një nga format e referimit”, (Lloshi, 2005: 307). Vëmë në dukje, me këtë rast, se referimi, presupozimi dhe ngërthimi bisedor në tekstin dramatik, janë elemente të kuptimit në nivelin më të thellë (të dytë, të tretë,) të një teksti bisedor (shkrimor), gjatë ndërveprimit gjuhësor, përmes aktit pragmatik.

1 Kujtojmë, me këtë rast, se teksti dramatik nuk është i njëjtë me tekstin teatror, se i pari ka si mjet shprehës vetëm fjalën e shkruar, kurse i dyti ka dhe elemetë të tjerë shprehës: aktrimin, skenografinë, etj.

2 Nga greq. deixis, të dëftesh me dorë. 


\section{Albanon}

Revistë kulturore

Le t'i shohim këta deiktikë (dëftues) ose indeksorë,- sipas termit në filozofi,(Lloshi, 2005: 307), apo tregorë,- sipas termit të përdorur nga Rrokaj, ( 2010: 205), duke i grupuar në dëftime të mitologisë dhe dëftime të aktualizimit.

Në dëftuesit mitologjikë te vepra dramatike "Akili” vëmë re persona të personazheve pjesëmarrës, fjalërues e veprues të miteve: Priamin, Paridin, Poliksenën, Akilin të cilët, në aktin e tyre bisedor dramatik, ndërveprojnë gjuhësisht me "zërat" e tyre ligjërimorë, sipas cilësimeve të tyre, me të cilat thirren dhe i drejtohen njëri-tjetrit, si dhe të strategjive të tyre të ndryshme të komunikimit, përgjatë dialogimit dinamik.

Priami: Urdhno ktu pran, o bir $i$ Thesalis, / Se ty të pret si dhanrrin e shtëpis/ Nashti Priami dhe n'vend t'birit t 'ka;/ Prandaj dëshronte sot për me të pal... Urdhno pra rri, në nj'an' t'yt vjhërr ke, / Mbë tjetrën an' Paridin n'mosh'n e re / Paridin t'yt kunat e djalin tïm/ I cili Trojës son' i suëll rrenim/...

Akili: O mbret me fam' i Trojës, un për nderl e quj qi të më preç ti muë kët herël Me buz' të qeshum dhe me fjal' miqsijel Ashtu si kunorës sate i ka hije.l Deri nashti luftuëm me të vërtetë, Por mbaskëndaj na do të rrijm' të qetël... (Haxhiademi, 1, 2000: 121,122,128).

Në citimin më sipër ne dallojmë dhe dëftuesit e kohës, ku shohim jo vetëm kohën historike, por dhe kohën e brendshme narrative, (kohën psikologjike), përmes modeleve të përfytyruara mendësie e fjalësimi të Greqisë antike, si dhe kohën e aktualizuar fizike, të shprehur me ndajfolje dhe shprehje ndajfoljore kohore dhe foljeve të kohës së tashme. Po kështu dallojmë dhe dëftuesit e vendit, ku vendoset situata e ndërveprimit gjuhësor dinamik dhe ku realizohet akti bisedor estetik, të cilët, përmes ndajfoljeve dhe shprehjeve ndajfoljore vendore, si dhe foljeve të kohës së tashme që tregojnë lëvizje në hapësirë konkrete, nëTrojën homerike. Dëftuesit që tregojnë akte ligjërimore paraprirëse, (kontekstuale), ku vendoset situata bisedore e aktualizuar, janë episodet periferikë të mitit trojan, që plotësojnë me kontekstin e tyre aktualizimin bisedor dramatik. Po kështu dëftuesit shoqërorë të statusit publik, hierarkik, familjar të personazheve pjesëmarrës bashkëligjërues që, gjithashtu shfaqen përmes aktualizimit fiksional:

Priami: Ja, bij, yt shoq na pret, u qelle mjaftl Dhe nusen ktu ta pruna djal' $i$ aftël...

Akili: Si ty t’pëlqej do t’bajm, o mbret hyjnorë; (Haxhiademi, 1,2000: 128).

Dëftuesit aktualizues, veç mjeteve gjuhësore që përmendëm më lart, (ndajfoljet dhe shprehjet ndajfoljore të kohës dhe vendit, koha e së tashmes 
të formave foljore, në një shikim intertekstual, të aktit ligjërimor të komunikimit të tragjedianit me lexuesit, "kënduesit e ndershëm”, siç i quan ai në parathënien paraqitëse të veprës dramatike në fjalë, me bashkëkohësit dhe bashkëkombasit e tij, (tragjedia"Akili” u shkrua në Vjenë), të viteve të 20 të shekullit të 20-të, mund t'i shohim këta tregorë të aktualizimit, në shumë elementë të tjerë, si: në ideolektin e të folmes gegërishte të Elbasanit, në traditat popullore të trevës në fjalë, në sintezat morale me vlerë të gjithëkohshme, në shoqërinë shqiptare të kohës, ku krimet politike për hakmarrje, sundim e pushtet, mbulohen me fjalësimin e lartë atdhetar e kombëtar, që përkojnë me vrasjet politike, të fshehura me tirada patriotike:

Priami (Poliksenës): Mendo ahere vetëm Trojën t’onël Qi ka për me shpëtumun për gjithmonël Se ti po t’bahesh gruj' e t'bir't t'Peleut, Ai ma s'do t'luftoj' kundër atdheut/...(Haxhiademi, 1, 2000: 96).

Veçori e tekstit dramatik është paraqitja e tij si një tekst i aktit të të folurit bisedor, të një bisede fiksionare estetike. Ndaj, dhe në veprën që shqyrtojmë autori përshkruan dhe rrëfen një kohë të largët antike, me një gjuhë të përpunuar poetike të letrarishtes dhe të së folmes së elbasanishtes së kohës së vet, të dhjetëvjeçarëve të parë të shekullit të 20-të . Kjo arrihet prej tij përmes konceptimit të tragjedisë letrare, si strukturë gjuhësore artistike, si dhe përmes protagonistëve të veprës në fjalë, të cilët, gjithashtu, përshkruajnë dhe rrëfejnë bëma dhe histori, qëndrime dhe sjellje fjalësore të botës dhe të marrëdhënieve e kumtimeve të tyre të mëparshme, për të argumentuar, mbështetur, bindur apo përligjur qëndrime apo veprime të tyre morale aktuale. Këto akte të foluri të tyre janë sa të hapura, (të cilat janë të rreme, siç janë argumentet e mbretit Priam për të shpëtuar Trojën, duke folur "me zemër të hapur", "me dhemshuri”, "me dashuri për të bijën”, “së cilës i do lumturinë"), aq dhe të fshehta (planit për hakmarrje ndaj Akilit, për bijtë e tij të vrarë, duke e futur në grackën e pabesisë heroin grek, përmes kurorëzimit të tij me martesë, me të bijën, Poliksenën të cilën Akili e dashuron). E gjithë kjo situatë dramatike është dhënë përmes një akti bisedor dinamik të Priamit, i cili, nga njëra anë kërkon të bindë Paridin, të dashuruar me Helenën, por jo trim, që të realizojë shpagimin ndaj kryetrimit të frikshëm, përmes të folurit atdhetar, por dhe përçmues, duke ia kujtuar gjithherë se ai ishte shkaktari i gjëmës për të vëllezërit e tij të sakrifikuar. Dhe në anën tjetër, Priami përdor strategjinë e atdhetarit, për të futur në grackë të bijën, që të kurorëzohet me Akilin, të dashuruar prej saj, por që Poliksena, për shkak të dhembjes për vëllezërit e vrarë nga Akili, nuk e çon në mendje të vërë kurorë me të. Pra, kemi dy strategji të ndryshme komunikimi, për të realizuar një 


\section{AlBanon}

Revistë kulturore

qëllim të vetëm, hakmarrjen ndaj heroit grek. Në strategjinë e komunikimit të parë, synohet të arrihet qëllimi përmes prekjes në dhembshurinë birnore dhe poshtërimit të bashkëfolësit, (Paridit), në strategjinë e komunikimit të dytë synohet të arrihet qëllimi, përmes ndjenjës së atdhetarisë dhe dashurisë e dhembshurisë prindërore (me Poliksenën), duke zotëruar kështu situatën bisedore të dilemave të bashkëbiseduesve të tij, në kontekstin historik dhe societal të kohës. E gjitha kjo, siç kemi vënë në dukje herë pas here, dhënë me një gjuhë sublime, me të cilën fjalësohet, përshkruhet dhe gjuhësohet bota e antikitetit dhe e kohës së vet të shekullit të 20-të, prej dramaturgut të shquar E. Haxhiademi:

Poliksena: Qëndro përpara meje n’kamb' o trim,/ Jo tyk' u ulun para gjunit tim!l Ngreu, pra, o djal hyjnor, ngreu ma përpjetë,/ Se t'mora vesh qi m'don me të vërtetë./...

Akili: Oh, ç'gaz pa mas!' T'vërteta, moj kaprolle, I pate t'gjitha fjalët qi më fole?/ Mos fol aq ambël ma, sepse thërrimel Ma bane zemrën muë me kto fjalimel...

Poliksena: O djal i lemun prej Thetidës s'detit, / Ta ruësh ti zemrën duhet prej tërmetit/ Të dashunis qi të ka kap me muë./.. (Haxhiademi,1,2000: 110).

Strategjia e komunikimit sublim, edhe në elementë të ligjërimit hipokrit, lajkatar dhe të pabesisë, paraqitet si mjeshtëri të foluri, si art gjuhësor pragmatik mashtrimi dhe krimi, që realizohet nga zotëruesi i aktit të bisedës, kur bashkëfolësi nuk është i përqëndruar e i vëmendshëm, për të kapur, për të dalluar në ngërthimin bisedor, atë që nuk është e thënë, si qëllim i vërtetë, nga folësi kryesor strategjik dhe që, përkundrazi, mbulohet, fshihet përmes asaj që thuhet, gjoja si e vërtetë prej tij, por që si përmbajtje thënieje, është e rremë.

\section{b. Referimi, presupozimi dhe ngërthimi bisedor në tekstin dramatik. Miti personal i autorit dhe miti kolektiv ${ }^{1}$, përmes aktit pragmatik.}

Autori bën një dramatizim të lirë të mitit të Akilit, duke dhënë një version personal të elementeve të tij fantastike. (Sepse një vepër artistike nuk synon vërtetësi historike, siç vumë në dukje në shqyrtimet paraprake teorike, në paraqitjen e kësaj trajtese). Kështu, sipas legjendës, heroin e sapolindur, e

1 Është e vërtetë se mitologia primitive ka patur një fillesë të fuqishme artistike, ekspresive, ka mbartur një ngarkesë të madhe poetike. Për këtë arsye, motivet dhe figuracioni mitologjik, formuan një tradita artistike kulturore që ndikoi dhe vazhdon të ndikojë deri në ditët tona mbi folklorin dhe artin e kultivuar", (Uçi,1982:90). 
ëma, perëndesha Tetis, e zhyti të birin në ujërat e lumit Stiks, duke e bërë të gjithë trupin e tij, të paprekshëm nga shigjetat (të pavdekshëm), përveç thembrës së këmbës, ku ajo e mbajti. Ndërsa në tragjedinë në fjalë, e ëma e zhyt në një koritë të mbushur me gjakun e zi të një gjiganti të vrarë nga Kiron Centauri:

Priami: Thetida kur ja lindi djal'n e rrallël Peleut, të shoqit, në të detit zallë,/ Atë e lan'me uj'n e detit t'kjarrtël Dhe sis' $i$ dha pastaj në gjin' e artël... E fut ahere mbrenda ke korital Akilin, djal'n e vogël, pra Thetida,/ Edhe me gjak'n e shtazës prap e lanël T'pavdekshëm tyk' kujtumun se e ban./ Por djalit n'themër t'kambës iu kish ngjitël Nji gjethe dhe kët vend sja kish ujitë/ Me gjak'n e shtazës perëndesha farel. (Haxhiademi,1,2000: 115).

Autori e realizon këtë ndërthurje të veprës së tij dramatike, të mitit të historisë antike dhe rikrijimit të lirë në kohën moderne, përmes referimit te burimi klasik, duke krijuar pamje çastesh dhe sekuencash dialogjike të herojve, të sjelljeve dhe qëndrimeve të tyre morale, në zgrip të jetës. Kështu, përmes personazhit të Akilit (në fakt, pavarësisht se tragjedia mban për titull emrin e tij, protagonisti kryesor, që drejton gjithë dialogimin, planin dhe fjalësimin e intrigës hakmarrëse e vrastare ndaj heroit, që përbën dhe strukturën thurëse të veprës, është Priami), autori, përmes referimit, fut në lojë kontekstin kulturor, dijen e lexuesit a të shikuesit, që ka marrë nga poemat homerike, dije dhe informacion që e aktivizon edhe përmes kontekstit kulturologjik, (episode që nuk lidhen drejtpërdrejt me argumentin kryesor narrativ dhe kumtues të veprës, por që hyjnë në lojën e kuptimësisëtë komukimit të plotë estetik). Veç kësaj, (kulturës klasike të një lexuesi të kultivuar, që hyn, pra, në situatën e komunikimit), poeti ynë dramatik, risjell episode e përshkrime plotësuese përmes intertekstit, (rrëfime, kujtime, sekuenca retrospektive, që bashkëfolësit, sjellin herë pas here, për përforcimin e argumenteve të tyre, ndaj bashkëbiseduesve që kërkojnë t'i bindin dhe t’i kthejnë në mbështetës e përkrahës të qëllimeve të tyre), si: ëndrra e tmerrshme e Hekubës, para lindjes së Paridit, i hedhjes së të sapolindurit në një gorgë (humnerë) dhe gjetjes së tij nga një bari që e rriti, motivi i mollës së artë, që djaloshit bari Parid, te kulloste bagëtinë, ia hodhi në dorë perëndia Merkur, që ai t’ia dhuronte perëndeshës më të bukur:

Paridi: Krejt i hutuëm me mollën n'dor' un mbetal Dhe ma të bukrën n'atë koh' s'e gjeta./ Kur për nji her' Junonal më kuptoi/ Dhe zuë me fjal' e lajka t'më gabojë:/ "Po m'dhe ti mollën muё" ajo më thotë,/ "Un ty do t'banj

1 Hera greke 


\section{AlBanon}

Revistë kulturore

ma trimin në kët' botë"./ "Do t'ap ty mendje shum' dhe dituni,/ Minerva m'thot' "po m'dhe mollën ti,/ "Po m'dhe muë mollën, ma t'bukrën gruë"/ M'thot'Afërdita 'kam me ta dhuruë./ Por muë dhurat'e t'fundëshmes ma shumë/ M'pëlqeu, moj motër, dhe si i hutuëm/Ja dhash asaj mollën tyk'u sha/ Nga dy të tjerat sa qi m'ban me qa./... (Po aty: 104).

Veç fjalësimit poetik, në strategjinë e komunikimit sublim, në këtë tragjedi, zë vend dhe ngërthimi bisedor dinamik, (implikatura në bisedë, ajo që, qëllimisht, nuk artikulohet si thënie, por që është pikërisht qëllimi i thënies, i ligjërimit bisedor), siç përmendëm dhe më parë, përmes të cilit, nënkuptohet ky tekst i pashprehur i thënies.

Priami (Poliksenës): Mendo atëhere vetëm Trojën tonël Qi ka për me shpëtumun për gjithmonë,/ Se ti po t'bahesh gruj e t'bir't t' Peleut, / Ai ma s'do t'luftoj' kundër atdheut,/

Poliksena: Por un prej atit s'mundem me kuptumun/Si mundet me më dhan' muë ke ai,/ Qi ma të shumtët djem ja ka varrumun/ Edhe e ka lan' t'shkret' në pleqëni!/ Kundrejt atij a ndoshta ka mendumun/ T' banj' ndonj' gja mbëshehtasi ai ditzi?/....

Priami (Akilit): Ma n'funt na vetëm mbetëm; pra un shtruë/ Dëshroj me ty, o djal,) me biseduë./ Anmik' i rrept ti muë ma par' më qe, / I dashtun si Paridi tash më je;/ Dikur ta lusja vdekjen ty gjithnji./ Të rrojsh me Poliksenën duë nashti,/Se m'vdiq Hektori, ruajtës $i$ atdheut,/ Dhe n'vend të tij kam djalin e Peleut.....

Akili: Mbretnesha s'ditka, m'thuë, qi t'bij’n marton?/ Ky lajm, të drejtën t'themi, po midhnon!....

Priami:Urdhno pra rri; në nj'an' t’yt vjehërr ke,/ Mbë tjetrën an’ Paridin n'mosh'n e re,/ Paridin tyt kunat e birin tim, / I cili Trojës son' i suëll rrenim./ Prej ktij kjo luft' e madhe na filloi,/ Prej teje kjo, o djal, do të mbarojë... (Haxhiademi, 1, 2000: 96,124,130,121).

\section{c) Deiksët mitologjikë dhe aktualizues në teksturën dialogjike.}

Nësekuencat dialoguese të mësipërme dallohen sërish lehtë deiktikët (dëftuesit e kohës, vendit, ata shoqërorë e familjarë të statusit të bashkëbiseduesve dhe të roleve pjesëmarrës të bashkëfolësve, duke e drejtuar (orientuar) qartësisht tekstin bisedor dhe ndërveprimin gjuhësor, te secili pjesëmarrës në aktin ligjërimor, te synimi pragmatik gjuhësor të tyre, drejt një komunikimi të 
realizuar plotësisht dhe marrëveshjesor mes bashkëligjëruesve. Kështu, përmes deiksëve (dëftuesve) mitologjikë ne shohim Mbretin Priam, në vargjet e parë poetikë, që i drejtohet vajzës së tij, me statusin dhe afërsinë e prindit (në numrin njëjës), në pallatin e Trojës, në vitin e fundit të luftës së saj me grekët, në kohën pas vrasjes së Hektorit, duke i kërkuar që të martohet me gjaksorin e bijve të tij, me qëllimin atdhetar për të shpëtuar Trojën e tyre, përmes krushqisë me armikun, (duke kaluar komunikimin e tij, nga statusi atëror në atë të mbretit, i cili ka përgjegjësi për fatet e atdheut, përgjegjësi që duhet të jetë e kuptueshme dhe pragmatike, ajo që mund të duket e pamendueshme dhe e papranueshme, kur vlen për largimin prej atdheut të rreziqeve dhe armiqve). Përmes komunikimit të Priamit me Akilin, (tashmë ai i drejtohet atij me statusin e dhëndrit, duke shkuar dhe më tej, duke e dashur po aq sa djalin e tij, Paridin e duke shkuar edhe më tej, duke e parë si djalë që ka zëvendësuar, Hektorin, djalin e tij të vrarë pikërisht nga Akili). Në aktin e të folurit monologjik (me veten) të Poliksenës, (që është strukturë po aq dialogike edhe "biseda" me veten, sipas Bahtin-it, (Dibra,- Varfi, 2005:154) dhe jo vetëm për psikanalizë artistike të karaktereve dramatikë), kemi gjithashtu deiktikët (dëftyesit) apo tregorët përkatës që lidhen me situatën e shqetësimit në të cilën realizon këtë komunikim ligjërimor me veten, por dhe dëftyesin e ligjëratës, të referimit të saj, në ligjërimet paraprirëse, në këtë rast, të tekstit bisedor të mëparshëm më të atin.

Ndërsa deiktikët (dëftuesit) aktualizues, siç vumë në dukje më sipër, dallohen përmes analizash më të thella të strukturës së tekstit. Ata kanë të bëjnë me dëftyesit në procesin e komunikimit të autorit me lexuesin, (me ç'status iu është drejtuar ai bashkëkohësve të vet dhe me ç'status na "drejtohet" ai neve sot. Ç’vlerë, ç’status i japim ne atij dhe mesazhit që kumton; kuptohet që jo vetëm atë të shkrimtarit, por dhe të intelektualit, idealistit dhe humanistit të qytetarisë së kohës së vet etj. Deiksët aktualizues, që janë kryesisht dëftyes të tekstit, janë të natyrës simbolike. Megjithatë dhe dëftyes të qartë aktualizues ne shohim në sekuencat me thënie të përgjithësuara, me vlerë përvoje e morale të gjithëkohëshme, që nuk lidhen drejtpërdrejt me kohezionin e bisedës, por me koherencën e saj, duke fuqizuar e plotësuar argumentin e thënieve aktuale të thelbit përmbajtësor të bashkëfjalërimit.

Akili: O mbret, sa nan' e shkret' hek për fëmin/ Nuk hjek i ati kurr, por pasunin/ Shikon ai t'i vejë mbar' si duhet/ Dhe lavdi për trimni të mos i shuhet./ Çdo nan' gjithmon' mundohet për fëmin/Me shpres'qi do t’i shoh fatbardhësin/...

Thënie kjo në konkekstin bisedor të situatës konkrete: 


\section{Albanon}

Revistë kulturore

Akili: Sot pra qi mbretënëshës i martohetl E bija dhe qi zemra do ti gzohet/ Asaj, ti nuk po don me i kallxuë?l E mir' kjo gja simë duket fare muë;/... (Haxhiademi, 1, 2000: 131).

\section{Sekuencë ligjërimore në ko-tekst dhe kontekst. Përsiatje kritike formaliste.}

Analiza e aspekteve tingullore, problemet e domethënies së saj në kuadër të poetikës si dhe lidhshmëria e tingullit dhe e domethënies në një tërësi të pandashme, -janë fazat më të rëndësishme të hulumtimeve formaliste, - sipas Roman Jakobson-it, (Dominantja, 2008: e-letrat,), ku në fazën e tretë është përpunuar nocioni i dominantes, e cila është një komponent qendror i veprës artistike që “i orienton”, i përcakton dhe i shndërron komponentët e tjerë, duke garantuar tërësinë e strukturës së një vepre letrare dhe duke i dhënë asaj veçanësinë. Dhe elementi që i jep veçanësinë një lloji të caktuar të gjuhës, e dominon tërë strukturën e veprës artistike. Te tragjedia "Akili", kemi vargun poetik të orientuar drejt dimensionit muzikor, si te arti romantik, ku dominantja ishte muzika, si vlerë sipërane e artit. Domethënia e situatës, rrethanës, kontekstit tragjik, në të cilën Akili, (përmes Priamit, i cili shfrytëzon me pragmatizëm, dashurinë e së bijës, për heroin e pathyeshëm grek), shkon nëpër rrjedhën e dialogjizmit estetik, me tensionin përmbajtësor të kumtit tragjik. Gjatë ndërshkëmbimit bisedor (me çiftet e thënieve të tyre) të protagonistëve, të cilët hyjnë në konflikt, si kontekst dhe realitet fizik e psikologjik, ashtu edhe në universin e ligjëratës, të ligjërimit, të diskursit dramatik. Në këtë rast, përcaktimi i funksionit estetik si dominante e veprës, na mundëson që të dallojmë, - sipas Jakobsonit,- hierarkinë e funksioneve gjuhësore të ndryshme, në kuadër të kësaj vepre, si: funksionin referencial, funksionin ekspresiv, emotiv etj. Në veprën në fjalë, funksioni estetik përfaqëson dominanten e mesazhit gjuhësor. Virtytet e heronjve klasikë, (në këtë rast të Priamit), nuk marrin parasysh ndjenjat njerëzore të bijve të tyre (dëshirës që kanë për të jetuar dashurinë e vet, pa u marrë me vrasje për hakmarrje: Paridi, Poliksena). Mesazh gjuhësor i cili jepet përmes mjetesh të gjuhës ekspresive, që i nënshtrohet funksionit vendimtar të veprës, nën ndikimin e dominantes së saj: sublimes estetike të fjalësimit të autorit, në përshkrimin dhe paraqitjen e botës sonë. Fjalësim letrar, ku Haxhiademi përshtat fjalën, gjuhën, të folurin e tij individual, ligjërimin e tij personal, idiolektin e tij artistik me botën mitike, duke realizuar komunikimin kumtues me bashkëkohësit e vet të kohës moderne.: 
Akili: Shtërgat' e luftës shkoi; për muë qetsijal E duhshme asht, se zemrën timet'shkretël E ka pushtumun krejt ma dashunija,/ Qi asht e idhët tepër në kët' jetë;/...O Afërdit', sa zjarr të madh më dhe!l Por ah, si zemrën time të përvluëmel Të thyëme fare dhe pa shpres' e pe,/...(Haxhiademi,1,2000:127).

"Kështu teksti poetik është i frymëzuar me magji tingujsh, është pothuajse një kompozim muzikor: fjalët tërheqin vëmendjen për veçoritë e tyre fonike, tingëlluese dhe lexuesi ka kënaqësi edhe vetëm kur i shqipton e i thotë me zë të lartë”, (Dibra,-Varfi, 2005: 106). Sepse ligjërimi poetik vijon më shumë me asosacione të lira, me sekuenca imagjinare dhe melodike, se sa me sekuenca kohore apo logjike, nga që përshkrimi është gjithnjë shprehës e subjektiv. Dhe me këtë vepër letrare, "dramatisti i parë i madh shqiptar, ndërton strukturën e konvencën e dramës neoklasiciste në shqip, me harmoni të brendshme, gati me baraspeshë matematikore, modelet shkrimore universale", (Hamiti, 2010: 152).

Koncepti "shkrim klasik" këtu nuk ka të bëjë me përkufizimin e gjinisë letrare, aq më pak me stilin, (sipas Hamitit, po aty) por si shkrim letrar që, duke tejkaluar kanonin e vjetër të zhanrit, ruan gjithnjë esencën tragjike të kuptimit. ${ }^{1}$

Në esenë e tij të njohur "Lindja e tragjedisë" (2001: 98), Niçe vëzhgon me mprehtësi se brendinë e mitit tragjik e përbën një ngjarje epike me heroin zulmëmadh në qendër. Po ku fshihet vallë ai mister, që vuajtja për fatin e heroit, ndodhitë e pikëllueshme, motivet e përkundërta, aq munduese të skenës, apo, po të shprehemi me gjuhën e estetikës, pse tërë ajo shëmtirë dhe çharmoni përsëri e përsëri tregohet, pse paraqitet në forma të panumërta, me një pasion të veçantë? E si ta shpjegosh këtë, në rast se thamë që nuk i shërben përftimit të ngazëllimit?

Fakti që jeta përmban raste të panumërta tragjedish, nuk mund të shërbejë si arsye për lindjen e kësaj apo të asaj forme arti, se arti nuk është thjesht imitim i realitetit objektiv, ai është plotësim metafizik i këtij realiteti. Miti tragjik, duke marrë pjesë në art, merr pjesë në kryerjen me sukses të detyrës iluministe që ka arti në përgjithësi, por ç’ndriçon, kur i paraqet dukuritë e botës përmes figurës së heroit tragjik? Më pak se çdo gjë na paraqet realen e kësaj bote... Dhe në këto çaste bota përjetoi mitin. E bëri për të na e treguar veten të përndritur? Vetëm si fenomen estetik, (Niçe, po aty) ekzistenca dhe

1 Ashtu si në "tragjeditë klasike të periudhës së klasicizmit të pjekur të Gëte-s: "Ifigjenia në Tauridë" dhe "Tasso"'.'. (Enciklopedia, 2006: 711), apo të mëvonshme, të Klastit: "Pentesilea",etj. 


\section{AlBanon}

Revistë kulturore

bota paraqiten si të përligjur... E kuptuar kështu, detyra e mitit është që të na bindë që, edhe e shëmtuara dhe joharmonikja është lodër artistike, në të cilën vullneti, në tërë ngazëllimin shekullor që ngërthen, luan me vetveten.

\section{Bibliografi:}

JAKOBSON, Roman: Dominantja, www.segur, e-letrat (ars poetika), Holandë, 2008

DIBRA, Klodeta - VARFI, Nonda: Gjuhësi teksti, SHBLU, Tiranë, 2005.

ENCIKLOPEDIA e përgjithshme e Oksfordit, Botimet ILK, Tiranë, 2006.

HAMITI, Sabri: Poetika shqipe, Botimet 55, Tiranë, 2010.

HAXHIADEMI, Et'hem: Vepra letrare, Faik Konica, Prishtine, 2000.

NIÇE, Fridrih: Lindja e tragjedisë, Botimet Uegen, Tiranë, 2001.

LLOSHI, Xhevat: Stilistika e gjuhës shqipe dhe pragmatika, Botimet Albas, Tiranë, 2005

RROKAJ, Shezai: Çështje të gjuhës shqipe, I, Botimet Albatros, Tiranë, 2007. 